\title{
PENGARUH LINGKUNGAN KERJA, KEPEMIMPINAN, KOMPENSASI DAN PELATIHAN KERJA PADA KETERIKATAN KARYAWAN HOTEL BERBINTANG 4 DI BATAM
}

\author{
Antony S \\ Universitas Internasional Batam \\ Antony.sentoso@yahoo.com
}

Abstract: This research was conducted with the aim to determine the effect of work environment, leadership, compensation and job training variables on employee engagement variables in star-rated hotels in Batam. This research was conducted using survey methods through questionnaires to as many as 380 respondents, namely employees from star-rated hotels in Batam. After being distributed directly to respondents, the questionnaire was collected and managed to get 340 questionnaires that were filled in completely and then the regression data was tested by the author using the SPSS program. From the results of data processing with SPSS it is known that there is a relationship on all variables studied. Based on the results of this study it is known the relationship between variables of work environment, leadership, compensation and job training on employee attachment variables, so that it is expected that the star hotel management can give greater attention to the variables studied above and manage employee attachments as one of the added values and advantages the hotel.

Keywords: hotel employee, leadership, working environment, compensation, training, and employee engagement

\section{PENDAHULUAN}

Batam merupakan salah satu kota industri yang terkemuka di Indonesia, dan juga merupakan salah satu pintu masuk utama bagi arus masuknya wisatawan asing dan nusantara. Batam merupakan gerbang utama arus masuk wisatawan mancanegara (wisman) di Kepulauan Riau. Batam pada 2017 lalu, sebanyak 1,5 juta wisman masuk melalui pelabuhan pelabuhan yang ada di Batam. Porsi besar Batam 72,5\% dari total 2,1 juta kunjungan wisman ke Kepri. Secara global, kunjungan wisman tumbuh sangat bagus dan potensi dari kunjungan wisatawan pun harus bisa dioptimalkan oleh pemerintah daerah dan pengelola industry wisata di Batam. Hal ini diharapkan dapat menunjang pertumbuhan ekonomi di Batam yang sedikit menurun karena berkurangnya jumlah kegiatan industri di bidang manufaktur, fabrikasi dan industri di bidang perkapalan (www.bpbatam.go.id).

Jumlah kunjungan wisman 2017 ke Kepri secara umum mengalami kenaikan sebesar 8,04\%. Kenaikan tersebut ditopang arus besar 1,1 juta wisman Singapura. Kencangnya denyut pariwisata pun positif bagi kas pendapatan daerah. Sektor pariwisata diklaim 
menghasilkan pendapatan asli daerah senilai Rp4,8 triliun. Target pertumbuhan sektor pariwisata yang lebih besar juga sedang dicanangkan oleh pemerintah daerah di Batam sekarang. Jumlah kunjungan wisman diharapkan kedepannya dapat mencapai 2,25 juta pada 2018 (www.bpbatam.go.id)

Industri perhotelan harus menyelaraskan perkembangan pariwisata di Batam, maka sektor dibidang industri perhotelan harus mampu mendukung dengan menyediakan sarana akomodasi yang dapat meningkatkan tingkat kinjungan wisatawan mancanegara dan juga wisatawan nusantara. Hotel merupakan jenis jasa akomodasi yang menyediakan fasilitas dan pelayanan penginapan serta jasa-jasa umum lainnya yang tinggal untuk sementara waktu. Jasa hotel dikelolah secara komersial atau untuk memperoleh profit keuntungan yang sebesar-besarnya dengan meminimalis pengeluaran tetapi tetap mengutamakan pelayanan yang terbaik untuk pelanggan. Industri perhotelan yang menjual jasa, pelayanan dari karyawan sangat di butuhkan agar mendapat bersaing dengan hotel berbintang lainnya, oleh karna itu pihak manajemen hotel harus dapat memperdayakan karyawannya dan meningkatkan komitmen pada hotel tempat mereka bekerja agar hotel dapat meningkatkan kinerja hotel secara umum (www.bps.go.id).

Bagi perusahaan yang bergarak di bidang jasa seperti hotel, di perlukan pelayanan yang optimal untuk mempertahankan kesetiaan pelanggan yang berkunjung. Pelayanan optimal yang diberikan bukan hanya sekedar melayani, tetapi upaya yang dilakukan untuk membangun sebuah hubungan kerja sama jangka panjang yang saling menguntungkan. Di Batam sendiri dengan terus meningkatnya jumlah pariwisata, maka jumlah hotel sebagai sarana akomodasi juga di perlukan untuk mendukung kegiatan pariwisata. Berdasarkan data, pertumbuhan hotel di Kota Batam terus meningkat setiap tahunnya yaitu pada tahun 2013 terdapat 170 hotel, pada tahun 2014 terdapat 176 hotel, pada tahun 2015 terdapat 184 hotel, dan pada tahun 2016 terdapat 190 hotel (www.bpbatam.go.id).

Batam yang merupakan salah satu gerbang wisatawan mancanegara mampu berkonstribusi dengan persentase yang besar terhadap jumlah seluruh kunjungan wisatawan mancanegara yang berkunjung ke Provinsi Kepulauan Riau yaitu sekitar 75,23 persen dari jumlah wisman yang berkunjung sebanyak 211.732 orang. Sedangkan bila di presentasekan terhadap jumlah kunjungan wisman secara nasional, maka wisman yang berkunjung ke Batam mencapai sekitar 15,38 persen dari total kunjungan wisatawan mancanegara secara nasional yaitu dari jumlah wisatawan mancanegara yang berkunjung ke Indonesia.

Keterikatan karyawan didefinisikan secara umum sebagai sebuah tingkat komitmen dan keterikatan seorang karyawan terhadap organisasinya dan nilai-nilainya. Ketika seorang karyawan merasa terikat dengan perusahaan tempatnya bekerja, maka ia menyadari tanggung jawabnya dalam tujuan bisnis dan memotivasi rekan-rekannya untuk keberhasilan tujuan organisasi (Ologbo \& Sofian, 2013). Sikap positif karyawan dengan tempat kerjanya dan sistem nilainya atau disebut sebagai hubungan emosional positif dari seorang karyawan terhadap pekerjaannya. Karyawan yang terikat pada pekerjaannya akan melampaui peran dan tugas mereka dengan samgat baik. Keterikatan karyawan dapat dipengaruhi oleh berbagai faktor, konsep tersebut telah berkembang dengan mempertimbangkan berbagai perilaku yang ditunjukkan oleh karyawan yang produktif secara positif. 
Lingkungan kerja merupakan kondisi yang ada di tempat kerja baik itu fisik maupun non fisik yang turut mempengaruhi pegawai dalam menjalankan pekerjaannya dan suasana yang dirasakan oleh pegawai di dalam organisasinya yang berkaitan dengan sikap dan tindakan rekan maupun pimpinan serta iklim kerja akan mempengaruhi keterikatan karyawan pada perusahaan.

\section{LANDASAN TEORI}

\section{Lingkungan Kerja dan Pelatihan Kerja}

Penelitian Anitha (2014) ini menganalisa pengaruh variabel lingkungan kerja, kepemimpinan, pelatihan kerja, dan kompensasi pada keterikatan kerja karyawan perusahaan dan usaha kecil di India. Keterikatan karyawan didefinisikan secara umum sebagai tingkat komitmen dan keterikatan seorang karyawan terhadap organisasinya dan nilai-nilai perusahaan tersebut. Ketika seorang karyawan merasa memiliki keterikatan pada perusahaan tempatnya bekerja, maka karyawan tersebut menyadari tanggung jawabnya dalam tujuan bisnis dan memotivasi rekan-rekannya untuk keberhasilan mencapai tujuan organisasi.

\section{Kepemimpinan dan Kompensasi}

Selanjutnya Ologbo dan Sofian (2013) meneliti mengenai pengaruh dari variabel kepemimpinan, citra perusahaan dan penghargaan dan kompensasi terhadap tingkat keterikatan karyawan. Penelitian ini dilakukan pada pegawai swasta yang bekerja di beberapa perusahaan di Malaysia. Keterikatan karyawan terhadap perusahaan menjelaskan seberapa besar seseorang merasa selalu bersemangat dan merasa senang dalam hal melakukan pekerjaannya. Metode survei melalui penyebaran kuesioner digunaan untuk mengumpulkan data untuk menguji model penelitian yang diajukan. Statistik teknik seperti t-test, korelasi dan regresi berganda digunakan untuk uji analisis data. Penelitian yang dilakukan oleh Naidoo dan Martins (2014) ini bertujuan untuk meneliti pengaruh budaya organisasi dengan tingkat keterikatan karyawan pada perusahaan di Afrika Selatan. Penelitian ini diharapkan dapat menjadi bahan rujukan dan referensi bagi manjemen perusahaan untuk meningkatkan tingkat keterikatan karyawan. Keterikatan karyawan terbukti berhubungan erat dengan berbagai keberhasilan bisnis. Meskipun sejumlah besar penelitian menyelidiki hubungan antara keterikatan kerja karyawan dan variabel organisasi, masih ada kelangkaan penelitian ilmiah tentang budaya organisasi dan dampaknya terhadap keterikatan kerja karyawan.

\section{Keterikatan Karyawan}

Ravikumar (2013) mendefenisikan keterikatan kerja karyawan sebagai gambaran hasil yang bagus dari nilai bisnis, dan menjadi barometer yang baik untuk keberhasilan dan kesehatan sebuah organisasi yang terbukti terhubung kuat dengan berbagai kesuksesan perusahaan, termasuk komitmen pada perusahaan, kepuasan kerja, produktivitas, inovasi, dan retensi karyawan dan hasil kerja yang positif. Jika suatu organisasi tidak memiliki karyawan yang berkomitmen untuk organisasi dan memiliki keterikatan dengan perusahaan tempatnya bekerja maka akan menemui kesulitan dalam implementasi dan eksekusi strategi kerja dan manajemen perubahan organisasi. Memahami kondisi di mana individu akan aktif terlibat dalam operasional perusahaan merupakan hal yang sangat penting untuk kemajuan karyawan 
dan perusahaan. Nilai-nilai organisasi, bersama dengan keyakinan, asumsi, harapan, sikap, filosofi, dan norma-norma, membentuk keterikatan kerja dan merupakan bagian integral dari identitas yang berbeda dari setiap organisasi. Dengan semakin meningkat rasa keterikatan karyawan pada pekerjaan mereka, maka akan semakin tinggi pula rasa memiliki dan memajukan perusahaan tersebut.

Naidoo dan Martins (2014) mendefinisikan keterikatan karyawan sebagai sebuah manifestasi dan ekspresi individu dalam perilaku tugas yang mendorong bekerja sama dengan orang lain, kehadiran yang bersifatpribadi pada perusahaan (fisik, kognitif, dan emosional), dan hubungannya pada peran dalam peningkatan kinerja perusahaan. Azeem et al., (2015) mendefenisikan keterikatan ada pada suatu kontinum, dan merupakan kebalikan langsung dari tiga dimensi kelelahan, yaitu kelelahan, sinisme, dan rasa ketidakefisienan. Dengan semakin tingginya keterikatan maka akan memepengaruhi kepatuhan seseorang pada organisasi dan akan berusaha untuk mencapai visi, misi dan tujuan perusahaan dalam melaksanakan pekerjaannya. Karyawan yang memiliki keterikatan yang tinggi dengan organisasi dicirikan dengan beberapa hal yaitu (1) karyawan memahami visi, misi, dan tujuan serta peraturan organisasi; (2) karyawan menyenangi pekerjaannya (3) karyawan memiliki motivasi kerja yang tinggi (4) karyawan selalu berusaha meningkatkan mutu kinerjanya (5) manajer dan karyawan saling menghormati; (6) karyawan mampu membangun tim kerja yang andal; dan (7) karyawan merasa sebagai bagian keluarga besar perusahaan.

\section{Pengaruh Lingkungan Kerja terhadap Keterikatan Karyawan}

Anita (2014) mendefenisikan lingkungan kerja sebagai hal yang berada disekitar lingkungan kerja karyawan yang dapat mempengaruhinya dalam melaksanakan pekerjaan yang dibebankan kepadanya. Lingkungan kerja yang baik dan menyenangkan akan meningkatkan motivasi karyawan dan tingkat keterikatan pada pekerjaannya. Suasana pekerjaan yang penuh persaingan yang sehat dan saling menghargai akan meningkatkan keterikatan karyawan pada perusahaan tersebut (Naidoo \& Martins, 2014).

Keterikatan karyawan pada sebuah perusahaan tempatnya bekerja merupakan kebutuhan perusahaan untuk mendapatkan keberhasilan dalam pengelolaan sumberdaya manusia dalam perusahaan tersebut. Semakin tinggi keterikatan karyawan dengan organisasi semakin baik kinerjanya dan akan semakin baik pula kinerja perusahaan tersebut. Penelitian sebelumnya dari Anita (2014), Naidoo dan Martins (2014) menemukan bahwa terdapat hubungan yang signifikan antara lingkungan kerja dengan keterikatan karyawan.

\section{Pengaruh Kepemimpinan terhadap Keterikatan Karyawan}

Kepemimpinan merupakan sebuah kemampuan dari seseorang dalam mengajak atau mempengaruhi orang lain dalam mencapai tujuan bersama (Swathi, 2013). Dalam penelitiannya tentang hubungan kepemimpinan dan keterlibatan kerja diketahui bahwa kepemimpinan transformasional mengarah ke keterikatan kerja karyawan yang lebih tinggi pada perusahaan-perusahaan sektor jasa di Pakistan. Ketika semua aspek kepemimpinan transformasional ini dipraktekkan oleh manajer yang dipimpinnya maka keterikatan kerja karyawan menjadi lebih tinggi. Pembicaraan tentang organisasi harus bekerja untuk 
mengembangkan dan menjaga keterlibatan karyawan yang membutuhkan hubungan dua arah antara pemimpin dan karyawan. Keterikatan karyawan merefleksikan tingkat produktivitas kerja karyawan. Ada banyak faktor lain selain manfaat yang bersifat moneter yang mempengaruhi keterlibatan karyawan.

Ologbo \& Sofian (2013) menyimpulkan bahwa ketika karyawan menganggap pemimpin mereka bertindak secara adil dan etis maka para karyawan ini juga diketahui akan meningkatkan keterikatan yang ditingkatkan dalam dedikasi, loyalitas dan pekerjaaan yang lebih focus dan peningkatan kinerja. Kepemimpinan etis bisa memastikan bahwa praktik etis dilakukan di seluruh organisasi, yang mungkin memiliki efek pada semangat dan kesetiaan pekerja. Pemimpin yang memiliki standar etika yang tinggi mendorong karyawan di organisasi untuk memenuhi level yang sama. Kemudian, etika karyawan akan memenuhi standar kualitas pekerjaan mereka, yang dapat meningkatkan reputasi perusahaan untuk produk yang berkualitas dan layanan yang meningkat yang merupakan salah satunya pentingnya keterimatan karyawan.

Karena itu, penelitian ini menambahkan etika kepemimpinan ke dalam kerangka konseptual di untuk mengukur pengaruh etika kepemimpinan pada keterikatan karyawan. Menurut Swathi (2013) bahwa para pemimpin yang berkharisma merupakan sumber bimbingan dan panutan. Tingkat kredibilitas dari pemimpin yang dapat dipercaya, kekuasaan, dan status sebagai teladan menarik perhatian para karyawan untuk mengikuti perilaku mereka yang dimodelkan. Pendeknya, kepemimpinan yang baik, jujur, penuh perhatian, individu berprinsip yang adil dan pengambil keputusan yang seimbang. Mereka berkomunikasi secara terbuka dengan karyawandan etika yang jelas. Penelitian sebelumnya dari Anitha (2014), Ravikumar (2013), Suharti dan Suliyanto (2012), dan Khuong dan Yen (2014) menegaskan terdapat hubungan yang signifikan antara kepemimpinan dan keterikatan karyawan.

\section{Pengaruh Kompensasi terhadap Keterikatan Karyawan}

Kompensasi diartikan sebagai pemberian imbalan pada karyawan yang diterima sebagai balas jasa atas pekerjaan yang dilakukan untuk perusahaan (Ravikumar, 2013). Kompensasi bisa berbentuk gaji, upah, tunjangan, bonus, insentif dan lain-lain. Sistem kompensasi yang baik dan memenuhi harapan karyawan akan membuat menguatnya nilai organisasi dalam mencapai tujuan organisasi. Menurut Sundaray (2012) kompensasi memiliki pengaruh yang besar dan erat hubungannya dengan keterikatan kerja karyawan. Kompensasi juga bisa berbentuk kepedulian perusahaan terhadap karyawannya. Sebuah organisasi yang baik harus memiliki sistem manajemen kompensasi yang bagus dan mampu meningkatkan keterikatan karyawan pada organisasi tersebut. Kompensasi juga bisa diberikan dalam bentuk pengakuan atau apresiasi atas pekerjaan karyawan dan mampu meningkatkan keterikatan karyawan pada perusahaan (Ologbo \& Sofian, 2013).

Karyawan bekerja tidak melulu untuk meraih kompensasi finansial saja namun juga nonfinansial seperti penghargaan personal dan karir. Karena itu tidak mungkin membangun keterikatan mereka hanya dengan pendekatan yang sangat bersifat struktural. Penelitian sebelumnya dari Ravikumar (2013), Ologbo dan Sofian (2013), Rana et al., (2013) 
mengatakan terdapat hubungan yang signifikan positif dari kompensasi terhadap keterikatan karyawan.

\section{Pengaruh Pelatihan Kerja terhadap Keterikatan Karyawan}

Menurut Lai et al., (2015) pelatihan adalah kegiatan yang dilaksanakan oleh manajemen perusahaan dalam meningkatkan keterampilan karyawan agar memiliki keterikatan kerja yang tinggi dan menjadi bagian dari kemajuan perusahaan. Karyawan yang diberikan pelatihan yang sesuai dengan pekerjaannya akan merasa lebih terikat pada pekerjaannya dan organisasi, keterikatan karyawan yang tinggi pada perusahaan juga memberikan dampak sikap, perilaku, dan perhatian yang lebih baik terhadap rekan kerjanya (Ologbo \& Sofian, 2013).

Menurut Manuel (2014) pelatihan yang sesuai akan memberikan karyawan keterampilan kerja yang lebih baik dan diperlukan dalam pekerjaannya. Pelatihan dan pengembangan karyawan merupakan salah satu kebutuhan perusahaan untuk meningkatkan keterikatan karyawan, apabila karyawan dapat pelatihan yang sesuai kebutuhan kerja maka akan dapat meningkatkan kinerja dan meningkatkan jumlah karyawan yang merasa terikat pada pekerjaannya. Pelatihan adalah sebuah metode pembelajaran yang efektif dalam membawa perubahan sikap dan kinerja karyawan (Azeem et al., 2013).

\section{Model Penelitian dan Perumusan Hipotesis}

Berdasarkan analisis dari diatas mengenai penelitian terdahulu tentang keterikatan karyawan maka penulis merumuskan sebuah model penelitian yang akan dijadikan sebagai bahan penelitian pada karyawan hotel bintang di Batam sebagai berikut:

Perumusan hipotesis dari penelitian di atas adalah sebagai berikut :

H1 : Lingkungan kerja berpengaruh signifikan terhadap keterikatan karyawan

$\mathrm{H} 2$ : Kepemimpinan berpengaruh signifikan terhadap keterikatan karyawan

H3 : Kompensasi berpengaruh signifikan terhadap keterikatan karyawan

H4 : Pelatihan kerja berpengaruh signifikan terhadap keterikatan karyawan

\section{METODOLOGI PENELITIAN}

Populasi dalam penelitian ini adalah sebanyak 2,600 karyawan dari 20 hotel klasifikasi bintang empat yang berada di Batam. Berdasarkan tabel Krejcie Morgan, dengan populasi sebanyak 2,600 maka sampel minimum yang diperlukan dalam penelitian ini berjumlah 335 responden. Namun sebagai bahan antisipasi bila terdapat kuesioner yang tidak kembali atau tidak diisi lengkap, maka penulis menyebarkan sebanyak 355 kuesioner untuk responden yaitu karyawan dari lima hotel bintang empat yang menjadi objek penelitian. Karyawan hotel dipilih sebagai objek penelitian karena sektor perhotelan menjadi salah satu andalan Batam dalam mendapatkan devisa daerah yang cukup penting sehingga hasil penelitian ini diharapkan nantinya dapat memberikan manfaat pada banyak pihak yang terlibat. Agar hotel dapat lebih maju maka dibutuhkan karyawan yang mampu bekerja maksimal dan memiliki keterikatan yang baik dengan hotel tempatnya bekerja. Hotel yang 
dipilih sebagai objek adalah hotel yang berada di kecamtan Lubuk Baja. Berikut penulis sajikan jumlah karyawan hotel bintang empat berdasarkan sumber yang diperoleh dari Dinas Tenaga Kerja Batam.

\section{Tabel 1}

Jumlah Hotel Bintang 4 di Kota Batam

\begin{tabular}{|c|c|c|c|c|}
\hline No & Nama Hotel & Kecamatan & Jumlah Karyawan & Jumlah Sampel \\
\hline 1. & Allium Hotel Batam & Batu Ampar & 205 Karyawan & - \\
\hline 2. & BCC Hotel \& Residence & Lubuk Baja & 83 Karyawan & 71 Karyawan \\
\hline 3. & Calmness Villa Batam & Sekupang & 55 Karyawan & - \\
\hline 4. & Crown Vista Batam Hotel & Lubuk Baja & 105 Karyawan & 71 Karyawan \\
\hline 5. & GGI Hotel & Batu Ampar & 62 Karyawan & - \\
\hline 6. & Golden View Hotel & Bengkong & 112 Karyawan & - \\
\hline 7. & Goodway Hotel Batam & Batu Ampar & 169 Karyawan & - \\
\hline 8. & Grand I Hotel & Lubuk Baja & 113 Karyawan & 71 Karyawan \\
\hline 9. & Harmoni Hotel Batam & Batu Ampar & 91 Karyawan & - \\
\hline 10. & $\begin{array}{l}\text { Harmoni One Convention } \\
\text { Hotel }\end{array}$ & Batam Kota & 104 Karyawan & - \\
\hline 11. & Harmoni Suites Hotel & Lubuk Baja & 83 Karyawan & 71 Karyawan \\
\hline 12. & $\begin{array}{l}\text { Horizon Ultima Kings } \\
\text { Batam Hotel }\end{array}$ & Lubuk Baja & 152 Karyawan & 71 Karyawan \\
\hline 13. & Harris Hotel Batam Center & Batam Kota & 115 Karyawan & - \\
\hline 14. & Harris Resort Waterfront & Sekupang & 133 Karyawan & - \\
\hline 15. & I Hotel Baloi Batam & Lubuk Baja & 103 Karyawan & - \\
\hline 16. & Nagoya Hill Hotel & Lubuk Baja & 92 Karyawan & - \\
\hline 17. & Novotel Hotel Batam & Batu Ampar & 200 Karyawan & - \\
\hline
\end{tabular}



18. Pasific Palace Hotel
Batu Ampar
Batu Ampar
Batu Ampar
20. Swiss Belhotel Harbour Bay
Total Karyawan
266 Karyawan
236 Karyawan
121 Karyawan
2600 Karyawan

355 Karyawan

Sumber: Dinas Tenaga Kerja Batam (2017)

Penelitian ini dikategorikan sebagi penelitian dasar yang mempunyai tujuan dalam mengembangkan sebuah teori, dimana teori yang dibahas dalam penelitian ini hanya digunakan untuk kepentingan lingkungan akademik (Indriantoro \& Supomo, 2012). Namun bila ditinjau dari sisi permasalahan, maka penelitian ini termasuk dalam penelitian kausal komparatif yaitu merupakan jenis penelitian dengan masalah berupa hubungan sebab akibat antara empat variabel independen yaitu kepemimpinan, lingkungan kerja, kompensasi dan pelatihan kerja terhadap keterikatan karyawan sebagai variabel dependen (Indriantoro \& Supomo, 2012), alat pengujian statistic yang digunakan adalah SPSS dengan menguji outlier, validitas, reliabilitas, normalitas, multikolinearitas, heterokesdatisitas, uji hipotesis (uji f, uji t dan uji $r$ square).

\section{HASIL PENELITIAN}

\section{Hasil Uji Kuantitatif}

\section{Hasil Uji Outlier}

Untuk mengetahui apakah terdapat data yang menyimpang dalam kuesioner yang dibagikan pada responden maka penulis melakukan uji outlier, dimana berdasarkan hasil pengujian ini terhadap 340 responden, tidak ditemukan adanya nilai z-score yang lebih kecil dari -3 dan atau lebih besar dari 3. Sehingga semua responden dapat diikutsertakan pada pengujianan berikutnya karena dianggap wajar dalam memberikan jawaban terhadap kuesioner yang dibagikan. Data yang dianggap menyimpang dari rata-rata akan dibuang dan tidak akan diuji lagi (Ghozali, 2011).

\section{Uji Kualitas Data Hasil Uji Validitas}

Berdasarkan hasil validitas yang ditampilkan diatas terhadap 25 pertanyaan dalam kuesioner terdapat 1 pertanyaan kuesioner yang tidak valid yaitu kepemimpnan 5 dengan nilai validitas 0,430 , sehingga pertanyaan tersebut tidak dapat diikutsertakan dalam proses pengolahan data selanjutnya. Uji validitas akan disimpulkan valid jika mempunyai nilai factor loading diatas 0,6 (Ghozali, 2011)

\section{Hasil Uji Reliabilitas}


Setelah melakukan uji reliabilitas, diperoleh nilai Cronbach alpha dari semua variabel menunjukkan bahwa semua variabel melebihi nilai batas konsistensi 0,6 (Ghozali, 2011) sehingga semua variabel yang digunakan dalam penelitian ini dinyatakan reliabel.

\section{Uji Asumsi Klasik Hasil Uji Normalitas}

Melalui uji normalitas dapat dilihat bahwa P_Plot menunjukkan data memiliki distribusi yang normal dan menyebar mengikuti garis diagonal, disimpulkan bahwa semua model regresi yang dipergunakan dalam penelitian ini layak dipakai karena memenuhi asumsi normalitas.

\section{Hasil Uji Multikolinearitas}

Hasil uji multikolinearitas terhadap variabel bebas tidak ditemukan nilai yang menunjukkan nilai tolerance di bawah 0,10 , yang artinya tidak ada korelasi antar variabel bebas. Hasil pengujian yang disajikan pada Tabel 4.9 menunjukkan nilai VIF kurang dari 10 dan nilai tolerance lebih dari 0,1. Jadi, dapat disimpulkan bahwa tidak terdapat multikolinearitas antar variabel bebas dalam regresi (Ghozali, 2001).

\section{Hasil Uji Heterokedastisitas}

Hasil uji heterokedastisitas dengan uji glejser terhadap variabel kepemimpinan, lingkungan kerja, kompensasi dan pelatihan kerja terhadap keterikatan karyawan. Variabel independen dan dependen terdistribusi normal dengan nilai diatas 0,05 maka dapat disimpulkan tidak terjadi heterokedastisitas.

\section{Uji Hipotesis}

\section{Hasil Uji F}

Uji F digunakan untuk menunjukkan apakah semua variabel independen mempunyai pengaruh secara bersama sama terhadap variabel dependen. Uji F dilakukan dengan melihat nilai signifikansi. Nilai probabilitas yang kurang dari 0,05 maka model regresi dapat digunakan untuk memprediksi variabel dependen (Ghozali, 2001). Hasil uji F diperoleh tingkat probabilitas sebesar 0,000 . Tingkat probabilitas 0,000 lebih kecil dari 0,05 sehingga model regresi tersebut dapat digunakan untuk memprediksi atau mengukur variabel komitmen organisasi sebagai variabel dependen.

\section{Hasil Uji t}

Berdasarkan hasil uji t diketahui bahwa nilai signifikansi dari H1 sebesar 0,024 dan nilai beta sebesar 0,116 maka disimpulkan bahwa terdapat hubungan dan pengaruh signifikan antara variabel lingkungan kerja terhadap keterikatan karyawan pada karyawan hotel berbintang di Batam. Temuan ini menunjukkan bahwa lingkungan kerja dalam sebuah hotel berpengaruh signifikan terhadap keterikatan karyawan pada hotel tempatnya bekerja. Hasil penelitian ini sesuai dengan penelitian sebelumnya dari Anita (2014) dan Naidoo dan Martins (2014). Berdasarkan hasil uji t diketahui bahwa nilai signifikansi dari $\mathbf{H 2}$ sebesar 0,021 dan 
nilai beta sebesar 0,151 sehingga dapat disimpulkan bahwa terdapat hubungan yang signifikan antara kepemimpinan terhadap keterikatan karyawan. Hasil penelitian ini menunnjukkan bahwa gaya kepemimpinan dari atasan akan berpengaruh terhadap tingkat keterikatan karyawan terhadap hotel tempatnya bekerja. Hasil penelitian ini sesuai dengan penelitian sebelumnya dari Anita (2014), Ologbo dan Sofian (2013), Swathi (2013), Suharti dan Suliyanto (2012), Bedarkar dan Pandita (2014), Ravikumar (2013), Sundaray (2014) dan Khuong dan Yen (2014).

Berdasarkan uji t diketahui bahwa nilai signifikansi dari $\mathbf{H 3}$ sebesar 0,001 dan nilai beta sebesar 0,180 sehingga dapat dikatakan bahwa tingkat kompensasi yang diberikan pada karyawan perusahaan di bidang perhotelan mempunyai dampak yang signifikan pada keterikatan karyawan pada hotel tersebut. Hasil penelitian ini sudah sesuai dengan penelitian terdahulu dari Alvi et al., (2014), Sundaray (2014), Swathi (2013) dan Ravikumar (2013). Berdasarkan hasil uji t menunjukkan bahwa nilai signifikansi $\mathbf{H 4}$ sebesar 0,000 dan nilai beta 0,378 sehingga dapat ditarik kesimpulan bahwa dalam penelitian ini pelatihan kerja yang diadakan perusahaan mempunyai pengaruh yang signifikan terhadap tingkat keterikatan pada karyawan hpotel berbintang. Hasil penelitian ini sesuai dengan penelitian dari Lai et al., (2015), Azeem et al., (2015), Manuel (2014) dan Anita (2014).

\section{Hasil Koefisien Determinasi (R2)}

Bila dilihat dari hasil uji koefisien determinasi (R2) yaitu 0,492 diketahui bahwa besar variabel independen mempunyai kemampuan sebesar 49,2\% dalam menerangkan hubungannya dengan variabel dependen. Tetapi ada 51,8\% faktor lainnya yang dijelaskan oleh variabel lain yang tidak diteliti dalam penelitian ini seperti budaya kerja dan kerjasama tim (Ravikumar, 2013).

\section{KESIMPULAN}

Berdasarkan hasil uji, hasil penelitian ini menunjukkan bahwa lingkungan kerja, kepemimpinan, kompensasi dan pelatihan kerja dapat meningkatkan keterikatan karyawan perhotelan. Hasil penelitian juga menunjukkan bahwa terdapat beberapa faktor lain yang dapat meningkatkan keterikatan karyawan seperti budaya kerja dan kerjasama tim yang tidak diteliti dalam penelitian ini.

\section{UCAPAN TERIMA KASIH}

Terima kasih penulis ucapkan kepada Ketua LPPM Universitas Internasional Batam Bapak Wisnu Yuwono yang mendukung penulis untuk terus melakukan penelitian, juga kepada Dinas Tenaga Kerja Batam yang memberikan sumber data dan informasi seperti perhotelan di Batam yang dengan baik memberikan informasi yang penulis butuhkan serta karyawan hotel bintang 4 di kecamatan lubuk baja BCC Hotel \& Residence, Crown Vista Batam Hotel, Grand I Hotel, Harmoni Suite Hotel dan Horizon Ultima Kings Batam atas kesediannya dalam mengisi kuesioner agar penelitian ini dapat berjalan dengan lancar dan bisa selesai dengan cepat. 


\section{DAFTAR PUSTAKA}

Alvi, K.H., Khan, M.A., Ahmed, A.A., dan Zulfiqar, M (2014) A Study of Employee Compensation and Employee Job Engagement on Banks of Lahore, Pakistan. Science International Journal (Lahore), 26 (5), 2411-2414 (2014)

Anitha J. (2014) Determinants of Employee Engagement and Their Impact on Employee Performance. International Journal of Productivity and Performance Management Vol. 63 No. 3, 2014

Azeem, M.F., Rubina dan Paracha, A.T (2013) Connecting Training and Development with Employee Engagement: How does it Matter? World Applied Sciences Journal 28 (5): 696-703, 2013

Bedarkar, M dan Pandita, D (2014) A Study on the Drivers of Employee Engagement Impacting Employee Performance. Social and Behavioral Sciences 133 (2014) 106 115

Ghozali, I (2011). Aplikasi Analisis Multivariate dengan Program SPSS, Badan Penerbit Universitas Diponegoro, Semarang

Hair, J.F., Black, W.C., Babin, B.J., dan Anderson, R.E. (2010). Multivariate Data Analysis. Seventh Edition. Prentice Hall, Upper Saddle River, New Jersey.

Indriantoro, N \& Supomo, B (2012). Metedologi Penelitian Bisnis. Yogyakarta : Edisi Pertama, Penerbit BPFE.

Khuong, M.N. dan Yen, N.H (2014) The Effects of Leadership Styles and Sociability Trait Emotional Intelligence on Employee Engagement - A Study in Binh Duong City, Vietnam. International Journal of Current Research and Academic Review Vol. 2 NO. 1 (January, 2014) pp. 121-136

Lai, P.Y., Lee, J.S., Lim, Y.X., Yeoh, R.G., dan Mohsin, F.H (2015) The Linkage between Training and Development and Co-Worker Support towards Employee Engagement in Hotel Industry. International Journal of Scientific and Research Publications, Volume 5, Issue 5, May 2015

Manuel, F.D (2014) The Effect of Training and Development on Employee Engagement. World Review of Business Research Vol. 2. No. 5.

Naidoo, P dan Martins, N (2014) Investigating the Relationship between Organizational Culture and Work Engagement. Problems and Perspectives in Management, Volume 12, Issue 4, 2014

Ologbo, A.C dan Sofian, S (2013) Individual and Organizational Factors of Employee Engagement on Employee Work Outcomes. International Journal of Business and Behavioral Sciences Vol. 3, No.3; March 2013

Ravikumar, T (2013) Study on Impact of Teamwork, Work Culture, Leadership and Compensation on Engagement Level of Employees in MSMES in India. International 
Journal of Advanced Research in Management and Social Sciences Vol. 2 No. 8 August 2013

Suharti, L dan Suliyanto, D (2012) The Effects of Organizational Culture and Leadership Style toward Employee Engagement and Their Impacts toward Employee Loyalty. World Review of Business Research Vol. 2. No. 5. September 2012. Pp. 128 - 139

Sundaray, B.K (2011) Employee Engagement: A Driver of Organizational Effectiveness. European Journal of Business and Management Vol 3, No.8, 2011

Swathi, S (2013) Effecting Employee Engagement Factors. International Journal of Scientific and Research Publications, Volume 3, Issue 8, August 2013 